Ethnic Considerations for Glaucoma

\title{
Ethnic Considerations for Glaucoma: A Review
}

\begin{abstract}
Matt Bawn ${ }^{1}$
Centro de Genética y Biología Molecular, Facultad de Medicina, Universidad de San Martín de Porres, Alameda del Corregidor 1535, La Molina, Lima, Peru. Tel: 51 (1)-365-2300 ext. 152,

Fax: 51 (1) -365-0487 Email: matt.bawn@earlham.ac.uk
\end{abstract}

\begin{abstract}
Glaucoma is undoubtedly a major worldwide disease and cause of blindness. The term glaucoma however encompasses a group of disorders with differing age of incidence, intraocular pressures and varying degrees of hereditability in which vision loss occurs through a characteristic mode of retinal ganglion cell death. There are also significant differences in frequencies of incidence and gene associations for this group of disorders amongst different groups of populations. The current literature often states definitive trends in incidence for ethnic groups that fail to take into account an overall genetic fine structure for these groups. The present review intends to present an overview of some of the background necessary to discuss the genetic basis of glaucoma before describing some of the literature concerning the illness in Gypsy, Japanese, Scandinavian, Latino (Mexican and Brazilian) and Sub-Saharan African populations. It is intended that this review will give the reader a clearer picture of the diversity of worldwide glaucoma presentation which perhaps prove to question the current Ethnic view.
\end{abstract}

Keywords: Glaucoma, Genetics, Ethnicity

\section{Introduction}

Glaucoma is a major worldwide cause of blindness present in all populations and affects from 2 to $10 \%$ of the global population. The term describes a group of diseases that are characterised by a progressive death of retinal ganglion cells (RGC) which causes increased vision loss and ultimately blindness. Glaucoma is characterised by the appearance of the iridocorneal angle (open versus closed), further classifications refer to developmental traits divided in to primary or secondary. Primary types may be further characterised by factors such as age-of-onset and by intraocular pressure 
Ethnic Considerations for Glaucoma

(IOP). Most cases of glaucoma are accompanied by elevated IOP. Pressure irregularities occur when there is an imbalance in aqueous humour produced by the ciliary body and its removal via the trabecular meshwork. It is currently believed that pressure increases are due to an obstruction in the outflow of aqueous humour and not by an increase in its production. Reduction of IOP in glaucoma's characterised by elevated levels has been shown to delay or prevent further damage and remains the only current risk-factor which may be successfully treated [Ahrlich 2009]. However, there is at present no universally accepted mechanism linking elevated IOP to RGC death. It is also a common feature of glaucoma literature that its incidence varies amongst different ethnic groups, with the highest incidence of POAG seen in persons of African descent followed by Latinos and then Caucasians. An examination of the literature however leads the reader to the conclusion that the factors describing the prevalence of different types of glaucoma's in different populations is more complex than this statement suggests. This review will aim to provide the reader with an introduction to the anatomical and biomolecular background related to glaucoma. After this has been presented, the review will focus on five geographical/ethnic areas (Gypsy, Japanese, Scandinavian, Brazil/Mexico and Sub-Saharan Africa) and describe the findings of the literature with regards to each. In an attempt to better address the complexity of the genetic considerations of glaucoma.

\section{Anatomical Regions Associated with Glaucoma}

The following is a brief description of the anatomical features often encountered when reading glaucoma literature. A diagram of the major features discussed in this section is shown in Figure 1.

Anterior Segment: Glaucoma is associated with the anterior segment of the eye, a series of structures that consists of the cornea, lens, iris, ciliary body, and aqueous humour drainage structures (trabecular meshwork, Schlemm's canal and the uveoscleral pathway ${ }^{1}$.

Retinal Ganglion Cells: These are a type of neuron located in the retina in the posterior segment of the eye that produces its output, via their axons, to the brain where the visual information is processed. It is the only neuron in the retina that generates an action potential. Ganglia provide relay points and connections between 
Ethnic Considerations for Glaucoma

different neurological structures in the body. The point where the RGCs exit the eye to form the optic nerve is known as the optic disk.

Ciliary Body: Is a circumferential tissue within the eye that is composed of the ciliary muscle and the ciliary processes. It has three functions; Firstly, the ciliary muscles control the degree of concavity of the lens in a process known as accommodation, second the lens is attached to the ciliary muscles via lens zonules that are maintained by the ciliary body and lastly aqueous humour, which provides most of the nutrients for the lens and cornea and maintains IOP, is produced in the ciliary processes.

Aqueous humour: Aqueous humour in glaucomatous (POAG) eyes has been found to contain elevated levels of transforming growth factor (TGF) - $\beta 2$ (1).

Trabecular Meshwork: is an area of tissue near the ciliary body that is responsible for removal of aqueous humour from the anterior chamber, the front area of the eye directly behind the cornea. Although the trabecular meshwork removes around $90 \%$ of fluid, it is assisted by the secondary uveo-scleral pathway that is responsible for the remainder.

Open-angle and Closed-angle: The drainage structures of the anterior segment are located in the angle formed by the intersection of the iris and cornea. Partial blockage of these channels leads to a gradual increase in IOP but maintains the open-angle. Movement of the iris however, may inhibit or narrow the drainage structures that in this case are described as having a closed-angle. In this situation IOP increases abruptly and is accompanied by severe pain.

Optic Nerve: In glaucoma, the width of the neuroretinal rim decreases with the concomitant enlargement of the cup (2). The enlargement of the optic disk cup is rarely seen in other optic neuropathies. Several disorders of the optic nerve such as Ischemic and Leber's optic neuropathies and compressive lesions of the optic nerve may be misdiagnosed as forms of glaucoma.

Lamina Cribrosa: A mesh-like structure in a scleral hole through which the optic nerve exits the rear of the eye. It is composed of a multilayered array of collagen fibres that locate into the sclerial wall forming a lattice through which the nerve fibres of the optic nerve run. It is thought to be involved in the maintenance of the pressure 
Ethnic Considerations for Glaucoma

gradient between the inside of the eye and surrounding tissue and bulges outward slightly due to IOP. Increased IOP levels increase the outward displacement of the lamina cribrosa causing the lattice to deform and pinch the optic nerve fibres and postulated to be a cause of the nerve damage in glaucoma (3).

\section{Mechanisms of RGC death}

It is currently believed that ultimately all RCGs in glaucoma are killed due to apoptosis. Different initial events lead to the triggering of this cycle and more than one such event may be involved in different glaucoma's. Initiator mechanisms currently accepted to play a role in apoptosis include; neurotrophin deprivation, oxidative stress, glial activation, excitotoxicity and ischemia (4).

Caspases: Whichever the type of glaucoma, RGCs ultimately die via apoptosis, a cascade of cellular events that leads to the programmed destruction of the cell. Apoptosis is controlled by the caspase (cysteine-aspartate proteases) family of proteins (5). There are two types of caspase proteins, initiator and effector. Effector caspases are normally present in healthy cells as pro-enzymes; they become active as apoptotic agents by cleavage of their pro-domain due to partial proteolysis by initiator caspases. Effector proteins are then subsequently able to cleave other cellular protein substrates and continue the apoptotic process. Caspases may be associated with apoptosis, necrosis or inflammation and to date 12 have been found in humans. Caspases 2, 3, 6, 7, 8, 9 and 10 are currently associated with apoptosis (2, 8, 9 and 10 being initiators and 3, 6 and 7 being effectors). Apoptosis may be triggered either extrinsically or intrinsically although both pathways converge on the activation of effector caspases 3 and 7 .

Extrinsic pathway: this is initiated by Fas ligand (FasL) or tumour necrosis factor (TNF) binding to transmembrane death receptors. Ultimately downstream executioner caspases digest the cellular contents resulting in its destruction.

Intrinsic pathway: Several factors are known to contribute to the intrinsic pathway for example, oxidative stress and neurotrophin deprivation. The initial steps of the intrinsic pathway are at present unclear however, they ultimately converge to the mitochondrion and trigger the release of cytochrome $c$ from the intermembrane space 
Ethnic Considerations for Glaucoma

to the cytoplasm [Green and Reed 1998] inducing the activation of pro-caspases and caspases $^{3}$. It has also been found that elevated IOP also triggers this release ${ }^{4}$.

Neurotrophic (NT) Factors: Are a family of proteins found both in the central and peripheral nervous system that control the survival and development of neurons (6). The family includes brain derived neurotropic factor (BDNF), ciliary derived neurotrophic factor (CDNF), nerve growth factor (NGF) neurotrophin-3 (NT-3) and neurotrophin-4 (NT-4/5). Neurotrophins are growth factors, secreted proteins that are able to signal target cells. These proteins bind to two types of receptors; the highaffinity tyrosine kinase receptors (TrKA-C) and the low-affinity common neurotrophin receptor (p75NTR), respectively forming either survival or death signalling complexes. These two receptors can either suppress or enhance each other's action [Lykissas 2007]. A major proposed cause of glaucoma is the effect on the RGCs of a loss of neurotrophic factors. It is theorised that in some cases of glaucoma, it is a disruption of the retrograde axonal transportation of neurotropic factors that leads to RGC apoptosis. A corollary of this hypothesis is the supposition that enhancement of the NT pathways would lead to an increased survival and viability of injured RGCs. Indeed, rat studies have revealed that elevated IOP leads to axonal transport obstruction of BDNF at the optic nerve head [Quigley 2000]. NT are produced at the retina [Seki 2005], although at the present time a complete picture of the interplay of NT from various origins at the RGC is lacking.

\section{Types of Glaucoma}

Primary Open Angle Glaucoma (POAG): Is the largest incidence type of glaucoma. The strong coincidence of this type of glaucoma among family members has lead to the application of model-independent and model-dependant genetic linkage studies. In most cases POAG does not follow a clear Mendelian pattern of inheritance, despite clear familial clustering [Garchon 2004]. Although there is no universal consensus, the age-of-onset is normally after 35 years, but prevalence in patients over 60 POAG indicates a multifactorial disorder involving multiple genes [Mabuchi ref1]. IOP levels may vary but are above the normal (12-20 $\mathrm{mm} \mathrm{Hg}$ ) range. 
Ethnic Considerations for Glaucoma

Juvenile-Onset Primary Open Angle Glaucoma (JOAG): Is a type of POAG further characterised by an early age-of-onset 5-40 (Under 40 and normally before 20 years of age).

Primary Congenital Glaucoma (PCG): A rare autosomal recessive form of glaucoma associated with developmental defects of the trabecular meshwork and characterised by elevated IOP manifested at birth or in early childhood, leading to ocular enlargement and corneal oedema [9]. It is currently believed that PCG is caused by developmental defects in the iridocorneal angle, differentiating it from POAG and has been associated with the CYP1B1 gene. Studies of particular pedigrees have revealed segregation of PCG and POAG, a factor that suggests shared or overlapping mechanisms could predispose patients to both forms of glaucoma.

Normal tension Glaucoma (NTG): Characterised by IOP levels $\leq 21 \mathrm{~mm} \mathrm{Hg}$. Is reported to have higher occurrence amongst Japanese than Caucasians [Shi 2013], representing more than two-thirds of glaucoma cases. This form of glaucoma was initially thought to be uncommon, however the Beaver Dam study since indicated that up to one-third of glaucoma instances may be classified as NTG. It is currently believed that this form of glaucoma may be less dependant on IOP for disease onset and progression, although this may be an oversimplification due to the current state of knowledge [Ahrlich 2009]. It should be noted however, that in common with other forms of glaucoma, patients who display asymmetrical IOP levels are found to have increased visual field damage in the eye with greater IOP [Stein Ferhat]. NTG has further features distinguishing it from elevated IOP glaucoma's, primarily a larger degree of visual field loss than is predicted due to the appearance of the optic nerve. NTG patients also display a tendency for localised nerve fibre layer defects and optic disk haemorrhages.

For NTG there is a difference in prevalence amongst different ethnic populations when compared to POAG. In Caucasians and African-Americans the prevalence ratio is $\sim 1$, for Koreans is $\sim 3$ but is above 10 for Japanese ${ }^{11}$ where it may represent around $80 \%$ of total glaucoma cases [Sugiyama 2012].

Pigmentary Glaucoma: Is a condition characterised by iris pigment distribution throughout the eye that leads to optic neuropathy associated with secondary open 
Ethnic Considerations for Glaucoma

angle glaucoma ${ }^{6}$. Above average IOP levels (29 mm Hg mean), thought to be due to trabecular meshwork obstruction by dispersed pigment are found, but may range from 24-56 mm Hg. Age of onset is 30-50 years and the disease is more prevalent (78$93 \%$ ) in men.

Exfoliation Glaucoma (XFG): XFG is a secondary glaucoma caused by exfoliation syndrome (XFS) in which the accumulation of abnormal microfibular components in the anterior segment of the eye reduces trabecular outflow. The prevalence of XFS increases with age ${ }^{7}$.

Axenfeld-Rieger (ARS): Is a rare autosomal disorder affecting the development of the abdomen, teeth facial areas and the anterior segment of the eye ${ }^{89}$, caused by the disruption of the differentiation and migration of neural crest cells ${ }^{10}$. Glaucoma develops in approximately $50-60 \%$ of individuals with ARS.

\section{Population studies of Glaucoma}

Gypsy: Gencik began the study of PCG in Slovakia by initially looking at non-gypsy populations (7). This enabled the determination of a baseline figure for the incidence of occurrence for the disease. An incidence of approximately 1:22,000 was found with the ratio of men to women affected 1.55:1. The expansion of the study to include Gypsy families found a high incidence of the disease that for Gypsies was expressed as autosomal recessive with complete penetrance, whilst for non-Gypsy populations it displayed multi-factorial inheritance. In Gypsies the disease was always manifest bilaterally compared to around $75 \%$ bilateralism in non-Gypsy cases (8). An estimated gene frequency of the autosomal recessive form of $2.8 \%$ and an incidence in Gypsy-populations of 1:1250 were determined (9). It was also observed that the disease displayed an early-onset enabling diagnosis shortly after birth in $82 \%$ of cases. The inbreeding coefficient of Gypsy populations was found to be three times higher than in non-Gypsy Slovakian populations (10). For Gypsy-populations familial incidence of PCG was $85 \%$ and kinship marriage instances of $45 \%$ (11). In a new phase of genetic investigation in Slovakia, Plasilova et al mapped PCG in Gypsypopulation to the GLC3A locus (12). More in-depth analysis revealed a homozygous $\mathrm{G} \rightarrow \mathrm{A}$ transition in nucleotide 1505 of exon 3 of the CYP1B1 gene to be responsible for PCG in Gypsy populations, causing a E387K mutation in the cytochrome P450 
Ethnic Considerations for Glaucoma

protein (13). The identification of a common DNA haplotype in all patients suggested to the authors that this mutation originated from a common ancestor, a factor they used to reassert their hypothesis of a founder effect to be responsible for PCG in gypsy populations first put-forward by Ferak et al (10).

The investigations outlined so far have been concerned with Slovakian Gypsy populations. In an examination of Bulgarian Gypsies however, Sivadorai et al found four mutations in CYP1B1 and previously seen in Indian populations to be associated with PCG in only $30 \%$ of cases. Furthermore, they reported the E387K mutation to be rare in both patient and control groups (14), reinforcing the hypothesis of a role of a founder effect in Slovak Gypsy populations. No evidence for the involvement of the MYOC gene was found in this study. A subsequent study of the Bulgarian Gypsies along with consanguineous Pakistani families indicated a mutation in the LTBP2 gene in $40 \%$ of all Gypsy PCG cases and in greater than $50 \%$ of CYP1B1 mutation absent cases (15). The authors contended that this mutation represents the major founder mutation in the overall Gypsy population. Comprehensive sequencing analysis of Bulgarian Gypsy populations indicated the five previous CYP1B1 and one LTBP2 mutations to be responsible for around $70 \%$ of PCG cases (16). It was also found that homozygosity for the $L T B P 2$ mutation presented a more clinically severe phenotype. A literature review of mutations in the CYP1B1 gene associated with PCG by a Chinese group found the E387K mutation in 80\% of cases in Gypsy populations (17). G61E was designated a founder mutation for Middle Eastern Populations and was found in $46 \%$ of cases. Founder mutations were not seen for Caucasian and Asian populations, although there was a clustering of mutations around certain residue numbers. The authors highlighted the consideration of ethnic and geographical factors in strategies for detection and treatment of PCG.

Japanese: In Japan NTG is responsible for around 80\% of all instances of glaucoma (18) (c.f. 10\% in Crete [Kozobolis 2000]). The first genetics based investigations by Japanese researchers tended to examine cohorts including POAG with NTG. Initial research focused on the MYOC gene as its involvement in POAG was discovered in other populations. Mutation rates in this gene were found to be $2.9 \%$ similar to other ethnic populations (19), initially suggestive of a minor role in the high-incidence of 
Ethnic Considerations for Glaucoma

NTG cases in Japan. Interestingly further study revealed an absence of mutations in the exons or introns of $M Y O C$ but rather in the promoter region (20), with one specific mutation $(-153 \mathrm{~T} \rightarrow \mathrm{C})$ present in $20 \%$ of open-angle glaucoma cases and $5 \%$ of unaffected controls. Subsequent examinations of NTG cases failed to find an association with the MYOC gene $(21,22)$. The OPTN gene was then examined with similar conclusions $(23,24)$, although a possible connection to POAG was suggested (25). Subsequently several other genes: AGTR2 (26), ETA (27), PON1 (28) were examined resulting in an inconclusive association, although a study of Korean NTG patients indicated a polymorphism in ETA to be more clearly associated with NTG (29). The intervening sequence of the OPA1 gene was shown to be associated with irregular IOP levels, as a polymorphism was seen in both NTG and HTG cases (30). More promising links to the NCK2 gene were found by microsatellite analysis (31). Several possible associations were found by the application of microsatellite analysis indicating GPDS1 (32), SRBD1 (33) and HK2 (34). The same method suggested CYPIB1 (35), and VAV2/VAV3 [XXXX], not be associated with NTG. The TLR4 gene was also found to be associated with the pathogenesis of POAG, XFG and NTG (36). As yet, however, none of these associations have explained the high incidence of NTG amongst the Japanese population, possibly indicating a likely candidate gene is still to be found. One possible reason for the inconclusive results of a large proportion of the outlined studies could be the investigation of un-related NTG cases and a lack of focus on NTG cases with a strongly defined familial history for which there would be a more probable genetic basis.

Scandinavia: In an Icelandic study of multiple families affected by XFS found that in all cases where the disease was present in two generations, transmission to the second generation was through an affected mother [Allingham 2001], which supports a hypothesis of genetic inheritance for XFS. The investigation of glaucoma and XFS in Scandinavia has revealed strong regional differences in prevalence even within the same country. POAG was found to be less frequent in southern Sweden and Denmark than in Central Sweden, Finland, Norway and Iceland (37). The authors of this study stated a role in the observed trend for low incidences of XFS in southern areas. XFS was found to be rare in Denmark compared to other Nordic countries (38), however, XFS and POAG were found to be common in northern Sweden where XFS affected 
Ethnic Considerations for Glaucoma

$25 \%$ of persons above 66 years old (39), XFS was also stated to increase the risk of glaucoma four-fold. A link between XFG and blood group antigens was suggested in a study from Central Norway (40). In this work no correlation was seen between blood type and XFS, however it was concluded that if an A1 blood group person developed XFS the risk of XFG developing was 7-times higher if that person were K1 positive rather than $\mathrm{K} 1$ negative. In an investigation into the function of the MYOC gene in Swedish patients, no mutations were found in patients with XFG (41), suggestive of a fundamentally different genetic basis for XFS than for POAG. A comparison of the co-morbidity of XFS and POAG in Norway found that acute cerebral-vascular and cerebral diseases were more common in patients with XFS than in patients with POAG (42). The role of IOP was found to be perhaps more complicated than previously thought in a Swedish study that found conversion to glaucoma to be twice as high in patients with elevated IOP and XFS than in IOP, age and gender matched control patients (43). The LOXL1 gene was shown to be involved in XFS in Sweden and Iceland where $25 \%$ of the general population were found to be homozygous for the highest-risk haplotype, with the risk of developing XFG 100-times greater for individuals with this haplotype compared with those with low-risk haplotypes [Thorleifsson 2007].

Brazil and Mexico: These countries have performed or have been the focus of a large degree of the genetic investigations involving glaucoma in Latin American populations. A general investigation into the prevalence of glaucoma in Southern Brazil in 2007 found the total incidence to be $3.4 \%$, with $2.1 \%$ in self-asserted white and $3.8 \%$ in non-white populations. The difference between the two populations was stated as not being significant.

Brazil: In Brazil mutations in the PITX2 gene were found to be responsible for a significant proportion of AR cases. One large family with AR however, showed no association to the PITX2, FOXC1 or RIEG2 genes indicating the existence of a novel locus for this disease [Borges 2002]. In 2006 two new structural alterations were seen in the FOXC1 gene in patients affected by AR [Cella 2006]. A polymorphism was also seen in the GJA1 gene with which the authors raised the possibility of its participation as a modifier gene. 
A 2002 study indicated CYP1B1 mutations may be responsible for 50\% of PCG cases in Brazil [Stoilov 2002], it also indicated mutations in this gene were more common in persons of European rather than African descent. In an investigation of PCG patients from Brazil and the US two CYP1B1 mutations were seen in both populations (Glu387Lys, 8037_8046dupTCATGCCCACC) [Sena 2004]. These mutations had also previously been seen in other PCG affected populations. The authors suggested the identification of these founder mutations in such ethnically diverse populations, indicated that the mutations might have a high carrier frequency that could be used for genetic screening for PCG. Novel mutations and polymorphisms were also found to be associated with severe PCG cases in 2010 [Della-Paolera 2010]. A specific mutation in exon 3 of MYOC (Cys433Arg) was found in association with high penetrance early-onset POAG [de Vasconcellos 2003], in which age of onset was before 40 years of age. The same mutation was seen in phenotypes characterised by varied ages at diagnosis causing JOAG and POAG with high IOP in 2006 [Povoa 2006]. One SNP $(-1000 C>G)$ was found to be equally distributed amongst POAG patients and control subjects [Kashahara 2011]. It was stated that this is possibly unrelated to the risk and severity of the disease in the Brazilian population. A more recent study has found a mutation in this gene (c.1187_1188insCCCAGA, p.D395_E396insDP) to be segregated with JOAG (44).

A 2009 study looked at five OPTN variants in association with POAG (T34T, E50K, M98K 691_692insAG and R545Q) [Caixeta-Umbelino 2009]. It was stated that no association was seen, however, the R545Q mutation was present in $23 \%$ of control subjects c.f. $10.1 \%$ of POAG possibly suggesting a role as a modifier gene.

Mexico: an investigation into the relation between IOP and glaucoma in Zuni native Americans in 1978 found low IOP and for it to be stable with age, no POAG or family history of POAG was found amongst the population [Kass 1978]. XFS was found to be almost 6 times more common in Spanish-Americans than in non-Spanish Americans in New Mexico, however no significant differences were found between the incidence of glaucoma in both populations (45). A recent study found variants in the LOXL1 gene to be associated with elevated risks of XFS and XFG in Mexican populations. Interestingly the risk was conferred via T-allele of the intronic rs 2165241 SNP and not by the world-wide high-risk G-allele rs3825942 [Jaimes 2011]. 
Ethnic Considerations for Glaucoma

The role of the CYP1B1 gene in PCG in Mexican populations remains unclear. One study found 4 novel mutations and a novel polymorphism [Messina-Baas 2007], whilst another found mutations in this gene to be rare $(<10 \%)$ and stated most nonBrazilian Latin American PCG cases were not due to mutations in the CYP1B1 gene (46).

Neither MYOC nor OPTN gene mutations were found to be involved POAG in persons of Mexican descent in a 2010 work by Allingham et al [Allingham 2010].

Sub-Saharan Africa: It is frequently stated in literature that the prevalence of glaucoma is higher in persons of African origin compared to Caucasians. A review of the studies carried out in Sub-Saharan Africa however, prove the case to be more complex than this statement suggests, perhaps due to an over-representation of US based studies on African American populations in the referenced literature. The incidence of POAG has also been found to differ widely amongst studies in different locations and ethnicities across Africa; 1.5\% South Africa (47) (40 years and above) $2.7 \%$ Zulus (48), 3.1\% Tanzania (49), Ivory Coast 2.1\% (50), 8.5\% Congo (51), Ghana 3\% (52) (mean age 36), Cameroon 5.8\% (53) (20-39 years).

Nigeria: A cross sectional study in 2002 found glaucoma to be responsible for blindness and low-vision in $0.32 \%$ of cases (54). In an investigation into glaucoma prevalence in an oncho endemic community the authors asserted that the prevalence of glaucoma is variant amongst different African populations (55). A northern Nigeria study of the Hausa-Fulani population found POAG in only $1.02 \%$ of the population aged 45 and above. The authors used this to suggest that glaucoma prevalence may not be uniformly high in all African populations but that the effects of age within their cohort could not be ruled out in arriving at this low figure (56). The Ibadan Glaucoma study in South-Eastern Nigeria found suspected and confirmed cases of glaucoma in $14.9 \%$ and $2.7 \%$ of cases (57). A study in the same area found blindness to be attributable to glaucoma in $15.8 \%$ of cases representing the $1.18 \%$ incidence of blindness (58).

South Africa: The 2003 Temba Glaucoma Study found glaucoma in 5.3\% of the candidates. POAG was found in $2.9 \%$ of cases overall whilst XFG was seen in $0.85 \%$ (59). XFS was found in $7.7 \%$ of Hlabisa and $6.0 \%$ of Temba candidates 40 years and 
Ethnic Considerations for Glaucoma

above with XFG accounting for 25\% of POAG cases (60). For XFS the major risk allele in LOXL1 was found to be reversed (A-allele) compared to other populations (G-allele) (61). Further investigations into the role of this gene in XFS found associations to the R141L and G153D SNPs consistent with Caucasian but not Asian cases (62). Possible MYOC mutations were seen in $4.4 \%$ of POAG cases (63).

Congo: A recent study found the incidence of XFS in patients to be $1.73 \%$ (c.f. 12 $16 \%$ in South African patients) (64).

Ghana: MYOC mutations were seen in $4.4 \%$ of POAG patients (65). A further study of MYOC mutations in 2003 asserted that many cases classified as POAG were in fact cases of closed-angle glaucoma (66). In the Akwapim-South district, glaucoma was prevalent in $8.5 \%$ of persons aged 40 and above, although interestingly no gender differences were seen in its prevalence (67). This was opposed to other studies revealing 2:1 male to female incidence of glaucoma in Ethiopia (68), Yemen [Saleh 2008] and Ghana (69). An investigation into mutations of the OPTN gene found no differences in the association of mutations between POAG groups and controls (70). In the Tema eye study, glaucoma was found in $6.8 \%$ of the population with a $2: 1$ male to female incidence ratio (69). A West-African study (Nigeria and Ghana) of individuals with type II diabetes found a strong association to WDR36 for IOP (71). An association was seen between rs12994401 (chromosome 2p16.3) and POAG in African Americans from North Carolina C-allele (72). This marker was also previously found to be associated with glaucoma in Barbados but via the T-allele [Jiao]. Liu et al also investigated the rate of mutations in the MYOC gene and found an overall mutation frequency of $1.4 \%$ in their African American cohort (73) (c.f. $2 \%$ in Tamil Nadu [Rose 2011], worldwide 2-4\% (74))

Cameroon: JOAG was shown to have familial association in $88 \%$ of cases and glaucoma was stated to be present in $7 \%$ of the population (75) clinic or POP.

Ethiopia: The frequency of subtypes of glaucoma amongst patients of a hospital in Jimma were as follows: XFS 35.2\%, POAG 32.8\% and PCAG 18.5\% (76). Beyond the reported high prevalence of XFS amongst the population, they also found 2.7:1 male to female incidence. A previous study in a hospital in Addis Ababa found POAG in $37.7 \%$ and $\mathrm{XFG}$ in $26.6 \%$ with male to female ratio $2: 1$ (77). An earlier study from 
Ethnic Considerations for Glaucoma

the same hospital found 40\% POAG, 18\% PACG, 2\% NTG and 2\% NTG with the same ratio of male to female incidence (68).

Mitochondrial haplogroups: A series of interesting investigations by Abu-Amero et al indicated the differences in glaucoma incidence amongst the Saudi Arabian population based on mitochondria DNA haplogroups. For POAG it was stated that African haplogroups L (excluding L2) indicate a higher risk for the development of the disease whilst the Eurasian haplogroup N1 (West Eurasian) was associated with reduced risk [REF]. For XFG haplogroups $\mathrm{T}$ (Eurasian with a high prevalence in the eastern Baltic) and L2 were found to confer susceptibility, whilst N1 was again associated with reduced risk (78). A study by the same group of a Ghanian (high frequency L2) cohort failed to find an association between the haplogroup and susceptibility to POAG (79).

\section{Discussion and Considerations}

Glaucoma is a disease that has received a large amount of attention by researchers from multiple disciplines. Much of the data for worldwide and ethnic statistics for frequency of incidence has come from population based, clinical and retrospective studies. Each of these methods of course, has its advantages and limitations but the mixing of data from each type, combined with the lack of consensus diagnostic parameters and methods leads to at best an unclear representation of the true global presentation of the disease. For example, one study indicated that screening of cases with IOP higher than $22 \mathrm{~mm} \mathrm{Hg}$ would miss $80 \%$ of POAG amongst its cohort (80). The method by which the IOP is determined may also be a consideration in the diagnosis of glaucoma. The most current method is Goldmann applanation tonometry. This method is optimized for central corneal thickness (CCT) values of $520 \mu \mathrm{m}$ with thicker CCT values leading to overestimates of IOP. CCT however is a highly heritable feature [Charlesworth IOVS 2010] the average value for which varies greatly between populations in the literature (518 $\mu$ m Japan [Suzuki 2005], c.f. 580 $\mu \mathrm{m}$ Germany [Feltgen 2001]). Mathematical corrections may be applied to correct for CCT when measuring IOP by this method however, it is not usually stated in the literature if and to what extent these factors are taken into consideration. Undoubtedly the level of training of healthcare providers also plays a major role in the diagnosis 
Ethnic Considerations for Glaucoma

and correct assignment of glaucoma in both clinical and community settings. In Northern India it was found that ophthalmic assistants missed up to $22 \%$ diagnoses when compared to doctors [Sinha Eye 2011]. It is also possible that some reported cases of glaucoma are misdiagnoses as some conditions (e.g. tuberculosis) have been said to mimic glaucoma with isoniazid put forward an optic nerve damaging agent [Stein Ferkat 1981].

With regards to the determination of genetic associations for glaucoma discussed above for different populations it may be said the investigation of PCG amongst Slovakian Gypsies yielded the clearest and most definite results. This however can, in a large part, be attributed to factors such as an obvious presentation of the disease due to its severity and young age of presentation and the ability to form and investigate large pedigrees due to certain specific cultural aspects of related cohorts. These factors could not in general be applied to the case of NTG in Japan, where investigators relied on screening for specific genes amongst mainly unrelated cohorts as an association to glaucoma was proposed for each tested gene. The success of these investigations remains minimal with the majority of NTG cases in Japan lacking an associated genetic cause at present even amongst families with a history of NTG. The example of XFS in Scandinavia demonstrates that the identification of cohorts with proven hereditable association of a disease can lead to successful identification of a candidate gene. The results described from Brazil and Mexico reinforce the difficulty in attributing specific genes to populations for POAG. They also however, highlight the positive gene associations that may be found when dealing with more severe forms of glaucoma with lower age of onset (PCG and JOAG). The sub Saharan African literature reveals a more complex incidence than may be described simply by references such as black or white (e.g. Scandinavia). The work of Abu Amero in particular proves to show a finer-grain association between populations and glaucoma. In fact, the importance of mtDNA variation in the treatment of AIDS is just beginning to gain attention [Ramallo Am J Phys Anthro 2013]. These attempts may be hampered however, due to the present incomplete picture of mtDNA variation across Sub-Saharan Africa. Cerny et al were able to determine that Chadic speaking populations in east Africa shared more mtDNA similarities with populations of the upper and middle Nile valley some 2000 km away [Cerny Ann Hum Biol 2004]. The authors stated that a continuous well-defined strategy was needed to put together a 
Ethnic Considerations for Glaucoma

better picture of Sub-Saharan Africa. It should also be remembered that African derived populations outside of Africa (i.e. The US, Caribbean and South America) do not display the same frequency and incidence of mtDNA haplogroups. It may also be likely that a fuller genetic picture (Y-chromosomal DNA) will yield patterns of association not seen at the present time. This may be true in particular for Scandinavian XFS, which displays twice the incidence amongst women than men.

\section{References}

1. Tripathi, R. C., Li, J., Borisuth, N. S., and Tripathi, B. J. (1993) Trabecular cells of the eye express messenger RNA for transforming growth factorbeta 1 and secrete this cytokine. Invest Ophthalmol Vis Sci 34, 2562-2569

2. Weinreb, R. N., and Khaw, P. T. (2004) Primary open-angle glaucoma. Lancet 363, 1711-1720

3. Morgan-Davies, J., Taylor, N., Hill, A. R., Aspinall, P., O'Brien, C. J., and Azuara-Blanco, A. (2004) Three dimensional analysis of the lamina cribrosa in glaucoma. Br J Ophthalmol 88, 1299-1304

4. Nickells, R. W. (1999) Apoptosis of retinal ganglion cells in glaucoma: an update of the molecular pathways involved in cell death. Surv Ophthalmol 43 Suppl 1, S151-161

5. McKinnon, S. J., Lehman, D. M., Kerrigan-Baumrind, L. A., Merges, C. A., Pease, M. E., Kerrigan, D. F., Ransom, N. L., Tahzib, N. G., Reitsamer, H. A., Levkovitch-Verbin, H., Quigley, H. A., and Zack, D. J. (2002) Caspase activation and amyloid precursor protein cleavage in rat ocular hypertension. Invest Ophthalmol Vis Sci 43, 1077-1087

6. Cui, Q., So, K. F., and Yip, H. K. (1998) Major biological effects of neurotrophic factors on retinal ganglion cells in mammals. Biol Signals Recept 7, 220-226

7. Gencik, A., Kadasi, L., Gencikova, A., and Gerinec, A. (1979) Notes on the genetics of congenital glaucoma. Ophthalmologica 179, 209-213

8. Gencik, A., Gencikova, A., and Gerinec, A. (1980) Genetic heterogeneity of congenital glaucoma. Clin Genet 17, 241-248

9. Gencik, A., Gencikova, A., and Ferak, V. (1982) Population genetical aspects of primary congenital glaucoma. I. Incidence, prevalence, gene frequency, and age of onset. Hum Genet 61, 193-197

10. Ferak, V., Gencik, A., and Gencikova, A. (1982) Population genetic aspects of primary congenital glaucoma. II. Fitness, parental consanguinity, founder effect. Hum Genet 61, 198-200

11. Gencik, A. (1989) Epidemiology and genetics of primary congenital glaucoma in Slovakia. Description of a form of primary congenital glaucoma in gypsies with autosomal-recessive inheritance and complete penetrance. Dev Ophthalmol 16, 76-115 
Ethnic Considerations for Glaucoma

12. Plasilova, M., Ferakova, E., Kadasi, L., Polakova, H., Gerinec, A., Ott, J., and Ferak, V. (1998) Linkage of autosomal recessive primary congenital glaucoma to the GLC3A locus in Roms (Gypsies) from Slovakia. Hum Hered 48, 30-33

13. Plasilova, M., Stoilov, I., Sarfarazi, M., Kadasi, L., Ferakova, E., and Ferak, V. (1999) Identification of a single ancestral CYP1B1 mutation in Slovak Gypsies (Roms) affected with primary congenital glaucoma. J Med Genet 36, 290-294

14. Sivadorai, P., Cherninkova, S., Bouwer, S., Kamenarova, K., Angelicheva, D., Seeman, P., Hollingsworth, K., Mihaylova, V., Oscar, A., Dimitrova, G., Kaneva, R., Tournev, I., and Kalaydjieva, L. (2008) Genetic heterogeneity and minor CYP1B1 involvement in the molecular basis of primary congenital glaucoma in Gypsies. Clin Genet 74, 82-87

15. Ali, M., McKibbin, M., Booth, A., Parry, D. A., Jain, P., Riazuddin, S. A., Hejtmancik, J. F., Khan, S. N., Firasat, S., Shires, M., Gilmour, D. F., Towns, K., Murphy, A. L., Azmanov, D., Tournev, I., Cherninkova, S., Jafri, H., Raashid, Y., Toomes, C., Craig, J., Mackey, D. A., Kalaydjieva, L., Riazuddin, S., and Inglehearn, C. F. (2009) Null mutations in LTBP2 cause primary congenital glaucoma. Am J Hum Genet 84, 664-671

16. Azmanov, D. N., Dimitrova, S., Florez, L., Cherninkova, S., Draganov, D., Morar, B., Saat, R., Juan, M., Arostegui, J. I., Ganguly, S., Soodyall, H., Chakrabarti, S., Padh, H., Lopez-Nevot, M. A., Chernodrinska, V., Anguelov, B., Majumder, P., Angelova, L., Kaneva, R., Mackey, D. A., Tournev, I., and Kalaydjieva, L. (2011) LTBP2 and CYP1B1 mutations and associated ocular phenotypes in the Roma/Gypsy founder population. Eur J Hum Genet 19, 326-333

17. Li, N., Zhou, Y., Du, L., Wei, M., and Chen, X. (2011) Overview of Cytochrome P450 1B1 gene mutations in patients with primary congenital glaucoma. Exp Eye Res 93, 572-579

18. Sugiyama, K. (2012) [A challenge to primary open-angle glaucoma including normal-pressure. Clinical problems and their scientific solution]. Nihon Ganka Gakkai Zasshi 116, 233-267; discussion 268

19. Kubota, R., Mashima, Y., Ohtake, Y., Tanino, T., Kimura, T., Hotta, Y., Kanai, A., Tokuoka, S., Azuma, I., Tanihara, H., Inatani, M., Inoue, Y., Kudoh, J., Oguchi, Y., and Shimizu, N. (2000) Novel mutations in the myocilin gene in Japanese glaucoma patients. Hum Mutat 16, 270

20. Suzuki, R., Hattori, Y., and Okano, K. (2000) Promoter mutations of myocilin gene in Japanese patients with open angle glaucoma including normal tension glaucoma. Br J Ophthalmol 84, 1078

21. Mabuchi, F., Yamagata, Z., Kashiwagi, K., Tang, S., Iijima, H., and Tsukahara, S. (2001) Analysis of myocilin gene mutations in Japanese patients with normal tension glaucoma and primary open-angle glaucoma. Clin Genet 59, 263-268

22. Ikezoe, T., Takeuchit, S., Komatsu, N., Okada, M., Fukushima, A., Ueno, H., Koeffler, H. P., and Taguchi, H. (2003) Identification of a new GLC1A mutation in a sporadic, primary open-angle glaucoma in Japan. Int J Mol Med 12, 259-261 
Ethnic Considerations for Glaucoma

23. Fuse, N., Takahashi, K., Akiyama, H., Nakazawa, T., Seimiya, M., Kuwahara, S., and Tamai, M. (2004) Molecular genetic analysis of optineurin gene for primary open-angle and normal tension glaucoma in the Japanese population. J Glaucoma 13, 299-303

24. Umeda, T., Matsuo, T., Nagayama, M., Tamura, N., Tanabe, Y., and Ohtsuki, H. (2004) Clinical relevance of optineurin sequence alterations in Japanese glaucoma patients. Ophthalmic Genet 25, 91-99

25. Funayama, T., Ishikawa, K., Ohtake, Y., Tanino, T., Kurosaka, D., Kimura, I., Suzuki, K., Ideta, H., Nakamoto, K., Yasuda, N., Fujimaki, T., Murakami, A., Asaoka, R., Hotta, Y., Tanihara, H., Kanamoto, T., Mishima, H., Fukuchi, T., Abe, H., Iwata, T., Shimada, N., Kudoh, J., Shimizu, N., and Mashima, Y. (2004) Variants in optineurin gene and their association with tumor necrosis factor-alpha polymorphisms in Japanese patients with glaucoma. Invest Ophthalmol Vis Sci 45, 4359-4367

26. Hashizume, K., Mashima, Y., Fumayama, T., Ohtake, Y., Kimura, I., Yoshida, K., Ishikawa, K., Yasuda, N., Fujimaki, T., Asaoka, R., Koga, T., Kanamoto, T., Fukuchi, T., and Miyaki, K. (2005) Genetic polymorphisms in the angiotensin II receptor gene and their association with open-angle glaucoma in a Japanese population. Invest Ophthalmol Vis Sci 46, 19932001

27. Ishikawa, K., Funayama, T., Ohtake, Y., Kimura, I., Ideta, H., Nakamoto, K., Yasuda, N., Fukuchi, T., Fujimaki, T., Murakami, A., Asaoka, R., Hotta, Y., Kanamoto, T., Tanihara, H., Miyaki, K., and Mashima, Y. (2005) Association between glaucoma and gene polymorphism of endothelin type A receptor. Mol Vis 11, 431-437

28. Inagaki, Y., Mashima, Y., Funayama, T., Ohtake, Y., Fuse, N., Yasuda, N., Fukuchi, T., Murakami, A., and Hotta, Y. (2006) Paraoxonase 1 gene polymorphisms influence clinical features of open-angle glaucoma. Graefes Arch Clin Exp Ophthalmol 244, 984-990

29. Kim, A., Bessho, K., Okawa, Y., Maeda, N., Tano, Y., Hirohara, Y., Mihashi, T., and Fujikado, T. (2006) Wavefront analysis of eyes with cataracts in patients with monocular triplopia. Ophthalmic Physiol Opt 26, 65-70

30. Mabuchi, F., Tang, S., Kashiwagi, K., Yamagata, Z., Iijima, H., and Tsukahara, S. (2007) The OPA1 gene polymorphism is associated with normal tension and high tension glaucoma. Am J Ophthalmol 143, 125130

31. Akman, A., Oram, O., and Aydin, P. (1998) Optic disc measurements with the 78 diopter lens, Zeiss 4-mirror contact lens and computerized image analysing system. Eur J Ophthalmol 8, 22-27

32. Nakamura, J., Meguro, A., Ota, M., Nomura, E., Nishide, T., Kashiwagi, K., Mabuchi, F., Iijima, H., Kawase, K., Yamamoto, T., Nakamura, M., Negi, A., Sagara, T., Nishida, T., Inatani, M., Tanihara, H., Aihara, M., Araie, M., Fukuchi, T., Abe, H., Higashide, T., Sugiyama, K., Kanamoto, T., Kiuchi, Y., Iwase, A., Ohno, S., Inoko, H., and Mizuki, N. (2009) Association of toll-like receptor 2 gene polymorphisms with normal tension glaucoma. Mol Vis 15, 2905-2910

33. Mabuchi, F., Sakurada, Y., Kashiwagi, K., Yamagata, Z., Iijima, H., and Tsukahara, S. (2011) Association between SRBD1 and ELOVL5 gene 
polymorphisms and primary open-angle glaucoma. Invest Ophthalmol Vis Sci 52, 4626-4629

34. Shi, D., Funayama, T., Mashima, Y., Takano, Y., Shimizu, A., Yamamoto, K., Mengkegale, M., Miyazawa, A., Yasuda, N., Fukuchi, T., Abe, H., Ideta, H., Nishida, K., Nakazawa, T., Richards, J. E., and Fuse, N. (2013) Association of HK2 and NCK2 with normal tension glaucoma in the Japanese population. PLoS One 8, e54115

35. Kamio, M., Meguro, A., Ota, M., Nomura, N., Kashiwagi, K., Mabuchi, F., Iijima, H., Kawase, K., Yamamoto, T., Nakamura, M., Negi, A., Sagara, T., Nishida, T., Inatani, M., Tanihara, H., Aihara, M., Araie, M., Fukuchi, T., Abe, H., Higashide, T., Sugiyama, K., Kanamoto, T., Kiuchi, Y., Iwase, A., Ohno, S., Inoko, H., and Mizuki, N. (2009) Investigation of the association between the GLC3A locus and normal tension glaucoma in Japanese patients by microsatellite analysis. Clin Ophthalmol 3, 183-188

36. Takano, Y., Shi, D., Shimizu, A., Funayama, T., Mashima, Y., Yasuda, N., Fukuchi, T., Abe, H., Ideta, H., Zheng, X., Shiraishi, A., Ohashi, Y., Nishida, K., Nakazawa, T., and Fuse, N. (2012) Association of Toll-like receptor 4 gene polymorphisms in Japanese subjects with primary open-angle, normaltension, and exfoliation glaucoma. Am J Ophthalmol 154, 825-832 e821

37. Ringvold, A. (1996) Epidemiology of glaucoma in northern Europe. Eur J Ophthalmol 6, 26-29

38. Alyahya, G. A., Hietanen, J., Heegaard, S., Kivela, T., and Prause, J. U. (2005) Exfoliation syndrome in Nordic countries: a comparative histopathological study of Danish and Finnish eyes with absolute glaucoma and uveal melanoma. Acta Ophthalmol Scand 83, 711-715

39. Astrom, S., and Linden, C. (2007) Incidence and prevalence of pseudoexfoliation and open-angle glaucoma in northern Sweden: I. Baseline report. Acta Ophthalmol Scand 85, 828-831

40. Ringvold, A., Blika, S., Elsas, T., Guldahl, J., Juel, E., Brevik, T., Hesstvedt, P., Hoff, K., Hoisen, H., Kjorsvik, S., and et al. (1993) The middle-Norway eyescreening study. III. The prevalence of capsular glaucoma is influenced by blood-group antigens. Acta Ophthalmol (Copenh) 71, 207-213

41. Jansson, M., Marknell, T., Tomic, L., Larsson, L. I., and Wadelius, C. (2003) Allelic variants in the MYOC/TIGR gene in patients with primary openangle, exfoliative glaucoma and unaffected controls. Ophthalmic Genet 24, 103-110

42. Ritland, J. S., Egge, K., Lydersen, S., Juul, R., and Semb, S. O. (2004) Exfoliative glaucoma and primary open-angle glaucoma: associations with death causes and comorbidity. Acta Ophthalmol Scand 82, 401-404

43. Grodum, K., Heijl, A., and Bengtsson, B. (2005) Risk of glaucoma in ocular hypertension with and without pseudoexfoliation. Ophthalmology 112, 386-390

44. Braghini, C. A., Neshich, I. A., Neshich, G., Soardi, F. C., de Mello, M. P., Costa, V. P., de Vasconcellos, J. P., and de Melo, M. B. (2013) New mutation in the myocilin gene segregates with juvenile-onset open-angle glaucoma in a Brazilian family. Gene 523, 50-57 
45. Jones, W., White, R. E., and Magnus, D. E. (1992) Increased occurrence of exfoliation in the male, Spanish American population of New Mexico. J Am Optom Assoc 63, 643-648

46. Zenteno, J. C., Hernandez-Merino, E., Mejia-Lopez, H., Matias-Florentino, M., Michel, N., Elizondo-Olascoaga, C., Korder-Ortega, V., Casab-Rueda, H., and Garcia-Ortiz, J. E. (2008) Contribution of CYP1B1 mutations and founder effect to primary congenital glaucoma in Mexico. J Glaucoma 17, 189-192

47. Salmon, J. (1993) Ethnicity and primary angle-closure glaucoma. $S$ Afr Med J 83, 921

48. Rotchford, A. P., and Johnson, G. J. (2002) Glaucoma in Zulus: a population-based cross-sectional survey in a rural district in South Africa. Arch Ophthalmol 120, 471-478

49. Buhrmann, R. R., Quigley, H. A., Barron, Y., West, S. K., Oliva, M. S., and Mmbaga, B. B. (2000) Prevalence of glaucoma in a rural East African population. Invest Ophthalmol Vis Sci 41, 40-48

50. Ahnoux-Zabsonre, A., Keita, C., Safede, K., and Tanoe, A. (1998) [Prevalence of primary chronic open-angle glaucoma in Ivory Coast]. J Fr Ophtalmol 21, 643-647

51. Kaimbo Wa Kaimbo, D., and Missotten, L. (1997) Glaucoma in Congo. Bull Soc Belge Ophtalmol 267, 21-26

52. Ntim-Amponsah, C. T. (1996) Mean intraocular pressure in Ghanaians. East Afr Med J 73, 516-518

53. Bella-Hiag, A. L., Ebana Mvogo, C., Ngosso, A., and Ellong, A. (1996) [Intraocular pressure in a young Cameroonian population]. J Fr Ophtalmol 19, 585-590

54. Abdu, L. (2002) Prevalence and causes of blindness and low vision in Dambatta local government area, Kano State, Nigeria. Niger J Med 11, 108112

55. Ekwerekwu, C. M., and Umeh, R. E. (2002) The prevalence of glaucoma in an onchoendemic community in South-Eastern Nigeria. West Afr J Med 21, 200-203

56. Murdoch, I. E., Cousens, S. N., Babalola, O. E., Yang, Y. F., Abiose, A., and Jones, B. R. (2001) Glaucoma prevalence may not be uniformly high in all 'black' populations. Afr J Med Med Sci 30, 337-339

57. Agbeja-Baiyeroju, A. M., Bekibele, C. O., Bamgboye, E. A., Omokhodion, F., and Oluleye, T. S. (2003) The Ibadan glaucoma study. Afr J Med Med Sci 32, 371-376

58. Adeoti, C. O. (2004) Prevalence and causes of blindness in a tropical African population. West Afr J Med 23, 249-252

59. Rotchford, A. P., Kirwan, J. F., Johnson, G. J., and Roux, P. (2003) Exfoliation syndrome in black South Africans. Arch Ophthalmol 121, 863-870

60. Rotchford, A. P., Kirwan, J. F., Muller, M. A., Johnson, G. J., and Roux, P. (2003) Temba glaucoma study: a population-based cross-sectional survey in urban South Africa. Ophthalmology 110, 376-382

61. Williams, S. E., Whigham, B. T., Liu, Y., Carmichael, T. R., Qin, X., Schmidt, S., Ramsay, M., Hauser, M. A., and Allingham, R. R. (2010) Major LOXL1 risk 
allele is reversed in exfoliation glaucoma in a black South African population. Mol Vis 16, 705-712

62. Rautenbach, R. M., Bardien, S., Harvey, J., and Ziskind, A. (2011) An investigation into LOXL1 variants in black South African individuals with exfoliation syndrome. Arch Ophthalmol 129, 206-210

63. Whigham, B. T., Williams, S. E., Liu, Y., Rautenbach, R. M., Carmichael, T. R., Wheeler, J., Ziskind, A., Qin, X., Schmidt, S., Ramsay, M., Hauser, M. A., and Allingham, R. R. (2011) Myocilin mutations in black South Africans with POAG. Mol Vis 17, 1064-1069

64. Kaimbo Wa Kaimbo, D. (2012) Pseudoexfoliation syndrome in Congolese patients. J Fr Ophtalmol 35, 40-45

65. Challa, P., Herndon, L. W., Hauser, M. A., Broomer, B. W., Pericak-Vance, M. A., Ababio-Danso, B., and Allingham, R. R. (2002) Prevalence of myocilin mutations in adults with primary open-angle glaucoma in Ghana, West Africa. J Glaucoma 11, 416-420

66. Herndon, L. W., Challa, P., and Allingham, R. R. (2003) Glaucoma in Ghana, West Africa: clinical features and the role of mutations in Myocilin. Ophthalmol Clin North Am 16, 631-637

67. Ntim-Amponsah, C. T., Amoaku, W. M., Ofosu-Amaah, S., Ewusi, R. K., Idirisuriya-Khair, R., Nyatepe-Coo, E., and Adu-Darko, M. (2004) Prevalence of glaucoma in an African population. Eye (Lond) 18, 491-497

68. Melka, F., and Alemu, B. (2006) The pattern of glaucoma in Menelik II Hospital Addis Ababa, Ethiopia. Ethiop Med J 44, 159-165

69. Budenz, D. L., Barton, K., Whiteside-de Vos, J., Schiffman, J., Bandi, J., Nolan, W., Herndon, L., Kim, H., Hay-Smith, G., and Tielsch, J. M. (2013)

Prevalence of glaucoma in an urban West African population: the Tema Eye Survey. JAMA Ophthalmol 131, 651-658

70. Liu, Y., Akafo, S., Santiago-Turla, C., Cohen, C. S., Larocque-Abramson, K. R., Qin, X., Herndon, L. W., Challa, P., Schmidt, S., Hauser, M. A., and Allingham, R. R. (2008) Optineurin coding variants in Ghanaian patients with primary open-angle glaucoma. Mol Vis 14, 2367-2372

71. Rotimi, C. N., Chen, G., Adeyemo, A. A., Jones, L. S., Agyenim-Boateng, K., Eghan, B. A., Jr., Zhou, J., Doumatey, A., Lashley, K., Huang, H., Fasanmade, O., Akinsola, F. B., Ezepue, F., Amoah, A., Akafo, S., Chen, Y., Oli, J., and Johnson, T. (2006) Genomewide scan and fine mapping of quantitative trait loci for intraocular pressure on $5 \mathrm{q}$ and $14 \mathrm{q}$ in West Africans. Invest Ophthalmol Vis Sci 47, 3262-3267

72. Liu, Y., Qin, X., Schmidt, S., Allingham, R. R., and Hauser, M. A. (2010) Association between chromosome 2p16.3 variants and glaucoma in populations of African descent. Proc Natl Acad Sci U S A 107, E61; author reply E62

73. Liu, W., Liu, Y., Challa, P., Herndon, L. W., Wiggs, J. L., Girkin, C. A., Allingham, R. R., and Hauser, M. A. (2012) Low prevalence of myocilin mutations in an African American population with primary open-angle glaucoma. Mol Vis 18, 2241-2246

74. Banerjee, D., Bhattacharjee, A., Ponda, A., Sen, A., and Ray, K. (2012) Comprehensive analysis of myocilin variants in east Indian POAG patients. Mol Vis 18, 1548-1557 
75. Ellong, A., Ebana Mvogo, C., Nyouma Moune, E., and Bella-Hiag, A. (2007) [Juvenile glaucoma in Cameroon]. Bull Soc Belge Ophtalmol, 69-77

76. Tenkir, A., Solomon, B., and Deribew, A. (2013) Glaucoma subtypes in Ethiopian clinic patients. J Glaucoma 22, 110-116

77. Giorgis, A. T., Mulugeta, A., Aga, A., and Deyassa, N. (2012) The spectrum of glaucoma presentation at Menelik II Hospital, Addis Ababa. Ethiop Med J 50, 259-264

78. Abu-Amero, K. K., Cabrera, V. M., Larruga, J. M., Osman, E. A., Gonzalez, A. M., and Al-Obeidan, S. A. (2011) Eurasian and Sub-Saharan African mitochondrial DNA haplogroup influences pseudoexfoliation glaucoma development in Saudi patients. Mol Vis 17, 543-547

79. Abu-Amero, K. K., Hauser, M. A., Mohamed, G., Liu, Y., Gibson, J., Gonzalez, A. M., Akafo, S., and Allingham, R. R. (2012) Mitochondrial genetic background in Ghanaian patients with primary open-angle glaucoma. $\mathrm{Mol}$ Vis 18, 1955-1959

80. Quigley, H. A., West, S. K., Rodriguez, J., Munoz, B., Klein, R., and Snyder, R. (2001) The prevalence of glaucoma in a population-based study of Hispanic subjects: Proyecto VER. Arch Ophthalmol 119, 1819-1826 
Figures

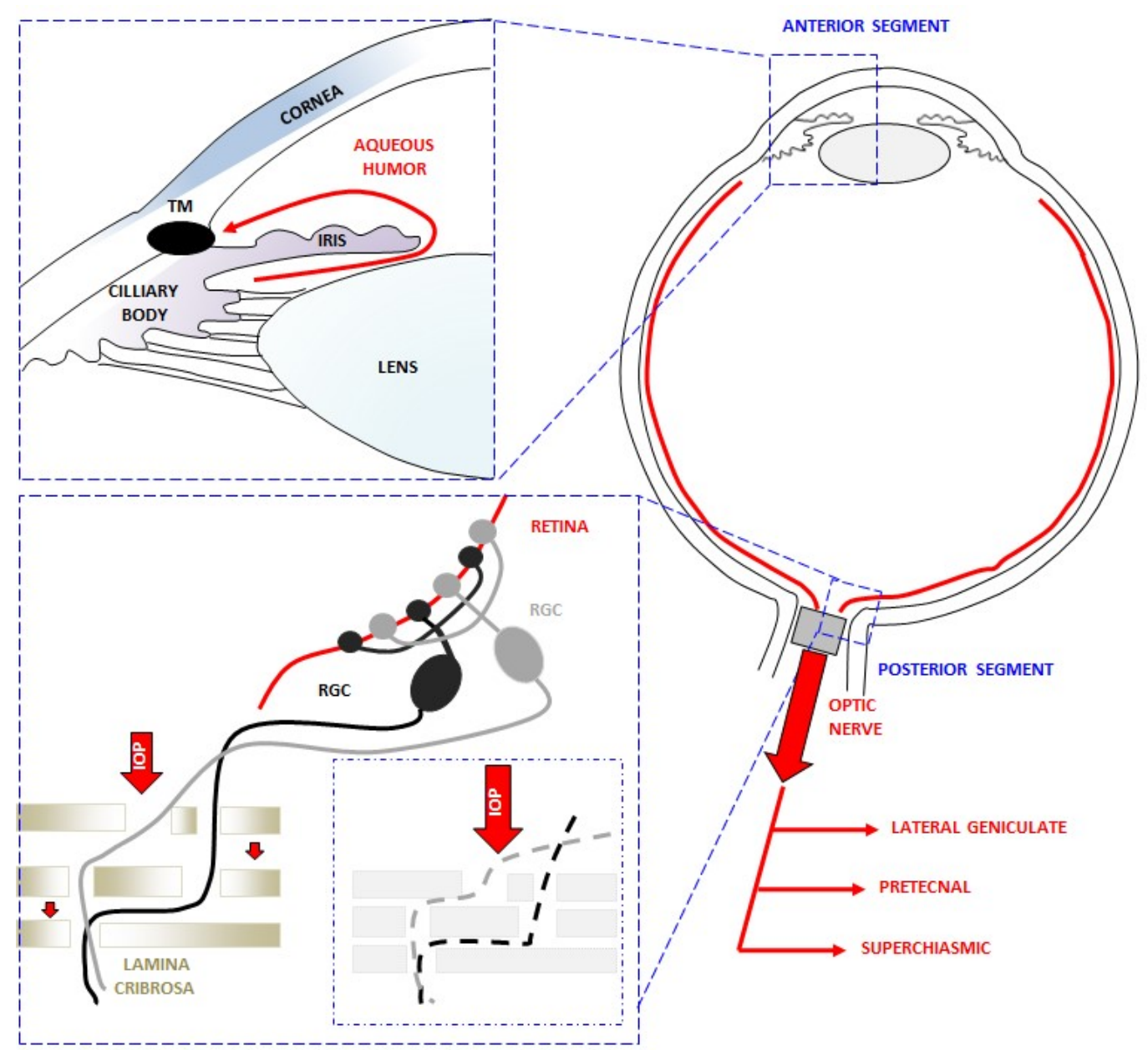

Figure 1, A diagram of the human eye showing the anterior and posterior segments (top and bottom insert sections respectively). TM: trabecular Meshwork, RGC: Retinal Ganglion Cells. In the insert for the posterior section the effect of increased Intra-Ocular Pressure (IOP) is shown for the Lamina Cribrosa (LC) (bottom right). In this case the increased IOP forces the LC to bow outwards, leading to compression of the RGC axons. 
Ethnic Considerations for Glaucoma 